\title{
CODIFICACIÓN Y DECODIFICACIÓN EN LA LEXICOGRAFÍA BILINGÜE: LA CREACIÓN DE UN DICCIONARIO BILINGÜE ESPAÑOL-LETÓN
}

\author{
GUNTA BRJUHOVECKA
}

Universidad de Letonia, Letonia

\begin{abstract}
Resumen. Codificación y decodificación en lexicografía bilingüe: la creación de un diccionario bilingüe español-letón. Partiendo tanto de la sugerencia del lexicógrafo Sandro Nielsen de que todo diccionario hay que considerarlo como una herramienta compleja que cumple una función lexicográfica, como de la conclusión del autor español Porto Dapena de que cada diccionario, según la finalidad concreta que persiga, debe ofrecer un contenido y una estructura diferente; este trabajo está dedicado a la lexicografía bilingüe poniendo de relieve las diferencias que existen entre la función lexicográfica comunicativa decodificadora (comprensión o interpretación) y la codificadora (expresión o redacción). Se analizan diferentes aproximaciones teóricas y prácticas con el fin de determinar los elementos de la macroestructura y microestructura necesarios para la decodificación y codificación en español y letón, resaltando la necesidad práctica de buscar nuevas soluciones para la compleja y hasta ahora poco tratada tarea de la codificación, especialmente en lo que se refiere a los diccionarios bilingües, así como profundizando el contacto de lenguas entre los hispanoparlantes y letonoparlantes. El trabajo, que forma parte del proyecto nacional de investigación 'Lengua letona', se lleva a cabo con vistas a la elaboración de un nuevo diccionario electrónico bilingüe español-letón/letónespañol con énfasis en la creación de materiales orientados a diferentes perfiles de usuarios.
\end{abstract}

Palabras clave: codificación, decodificación, diccionario electrónico, lexicografía bilingüe

\section{INTRODUCCIÓN}

En un reciente estudio sobre la historia y la calidad de diccionarios bilingües publicados, en los que se contrastan el español y letón (Brjuhovecka y Rozenberga, 2015), se constató que los diccionarios más recientes, español-letón de 2004 y letón-español de 2006, son mejorables en una serie de aspectos, lo cual lleva a la idea de que sería interesante compilar un diccionario nuevo y más moderno. 
Ante semejante tarea, merece la pena volver a los inicios y hacer las preguntas: ¿Qué es un diccionario? ¿Para qué sirve un diccionario? ¿Quiénes lo utilizan?

Entre los autores que ofrecen respuestas a ello cabe mencionar al lexicógrafo Porto Dapena. El diccionario, dice, responde a unas necesidades concretas: resolver las dudas que acerca de las palabras puedan surgir a los usuarios de la lengua y 'tratar que esta resolución de dudas sea lo más rápida, eficaz y precisa posible', por eso cada diccionario, según la finalidad concreta que persiga, ofrece un contenido y una estructura diferente (Porto Dapena, 2002: 35).

Dicho de otro modo, el factor determinante de todos los elementos del diccionario es la función lexicográfica. Por función lexicográfica entendemos, 'el objetivo para el que se ha diseñado o utilizado la obra de referencia' (Hartmann, 1998: 60), o, también 'el tipo de ayuda que el diccionario puede prestar a un tipo de usuario específico en un tipo específico de situación extra-lexicográfica en la que alguien puede consultar el diccionario para encontrar ayuda.' (Nielsen, 2002).

Las funciones lexicográficas se clasifican en dos grupos: 1) las que dependen del texto (funciones comunicativas), y 2) las que son independientes del texto (funciones cognitivas). En las funciones comunicativas se incluye la ayuda para traducir, comprender (decodificar) o redactar (codificar) textos, mientras que en las funciones cognitivas se incluye la ayuda para obtener conocimientos independientes de las actividades comunicativas, es decir, conocimientos enciclopédicos y/o lingüísticos (Nielsen, 2002 y 2013: 356).

El diccionario bilingüe, sobre todo, es una herramienta de ayuda para las tareas de codificación y decodificación.

Este estudio pretende dar respuestas a la siguiente pregunta: en la combinación de lenguas española y letona, ¿cuáles son los elementos lexicográficos concretos que se necesitan para la codificación? ¿Y para la decodificación? ¿Qué es lo que debe incluirse en la macro y microestructura? Dicho de otra forma, ¿acerca de qué queremos informar a ciertos usuarios del diccionario bilingüe, y cuál sería la mejor forma de hacerlo?

\section{MATERIALES Y MÉTODOS}

Para estudiar el problema, recurrimos a: 1) manuales de lexicografía, 2) literatura sobre la lexicografía bilingüe, 3) literatura sobre la lexicografía monolingüe dedicada a estudiantes de lengua extranjera, 4) manuales de gramática del español y del letón, 5) diccionarios bilingües en varias combinaciones de lenguas (español, letón, inglés, alemán y ruso), 6) diccionarios monolingües del español y del letón. Prestamos atención tanto a autores que destacan internacionalmente, como a autores españoles y letones, ya que podrían tener un punto de vista diferente.

Recopilando recomendaciones de la literatura estudiada, en especial en lo relativo a las necesidades de diferentes tipos de usuarios y a los elementos 
lexicográficos a incluir en diccionarios bilingües, y teniendo en cuenta ejemplos de diferentes diccionarios ya publicados, elaboramos varios artículos lexicográficos de un potencial diccionario electrónico español-letón y letónespañol desde las perspectivas de diferentes usuarios. Como lemas de dichos artículos escogimos palabras de uso frecuente (entre las 5000 palabras más frecuentes en cada idioma).

Para conocer la frecuencia de lemas en el español, empleamos el Corpus de Referencia del Español Actual (CREA) de la Real Academia Española, que incluye 160 millones de formas, de textos escritos y orales producidos entre 1975 y 2004 en España y en países hispanoamericanos, disponible en www.rae.es.

A su vez, para conocer la frecuencia de lemas en el letón, empleamos el corpus de lengua letona de la Universidad de Letonia, denominado en letón Lidzsvarots mūsdienu latviešu valodas tekstu korpuss, disponible en www.korpuss.lv. Contiene 5,5 millones de formas de textos escritos producidos entre 1991 y 2009. Tuvimos en cuenta que los datos de la frecuencia de lemas obtenidos de este corpus, a causa de su limitado número de formas, son solo orientativos, pero eran los únicos datos disponibles en el momento.

A falta de un corpus de textos bilingüe, para la selección de fuentes seguimos uno de los métodos recomendados por Atkins y Rundell: partir de varios diccionarios monolingües existentes, modificando la macro y microestructura original y realizando consultas adicionales en corpus de textos y en diccionarios bilingües.

Para limitar el estudio, utilizamos solo tres categorías de palabras: sustantivos, adjetivos y verbos. Preparamos cada artículo lexicográfico en dos versiones: versión codificadora y versión decodificadora. Finalmente, comparamos la versión codificadora con la versión decodificadora para determinar las diferencias.

Escogimos como perfiles de usuarios a estudiantes de diferentes niveles, pero sobre todo nivel intermedio y avanzado, según recomendación de Lew (2004: 17-19), así como profesores y traductores. Esta elección se debe, primero, a la alta demanda por parte de estudiantes de lengua extranjera (Adamska-Sałaciak, 2013: 216; Bogaards, 2003: 27; Cano Ginés, 2003: 11) y también porque si se elabora un diccionario amplio destinado a profesores y traductores, más tarde podría servir como base para diccionarios más reducidos (Balode, 2012: 57-58).

\section{ANÁLISIS DE LOS DATOS: DIFERENCIAS ENTRE LA CODIFICACIÓN Y LA DECODIFICACIÓN}

Para la decodificación, el usuario está interesado en el significado de la palabra en la lengua origen. Por eso algunos autores, como Haensch, Atkins y Rundell, creen que para la decodificación es suficiente con una mera lista de equivalencias en la lengua nativa, mientras que para la codificación se necesita cuanta más información posible. Otros, como Adamska-Sałaciak, señalan que también en los diccionarios decodificadores es recomendable discriminar las equivalencias. 
Para la codificación, en cambio, el usuario está interesado en la pronunciación, la sintaxis y las colocaciones de las equivalencias proporcionadas. Un diccionario bilingüe de codificación debe incluir información detallada sobre la discriminación entre las equivalencias y sobre su uso (incluida información sobre las colocaciones), la gramática y la fraseología, así como ejemplos de uso.

En la Tabla 1 se puede observar un ejemplo de cómo cambia la perspectiva dependiendo de quién sea el usuario del diccionario, así que en español y en letón es posible contrastar en cuatro formas diferentes: 1) diccionario español-letón para usuarios de habla hispana, 2) español-letón para usuarios de habla letona, 3) letón-español para usuarios de habla hispana, y 4) letón-español para usuarios de habla letona.

Tabla 1 Cuatro tipos de diccionarios en la combinación de idiomas español y letón

\begin{tabular}{|c|c|c|c|c|}
\hline & diccionario & tipo & funciones cognitivas & $\begin{array}{c}\text { funciones } \\
\text { comunicativas }\end{array}$ \\
\hline & $\begin{array}{l}\text { español-letón } \\
\text { para usuarios } \\
\text { de habla } \\
\text { letona }\end{array}$ & decodificación & $\begin{array}{l}\text { - adquirir información semántica } \\
\text { y gramatical sobre el español } \\
\text { (L2); } \\
\text { - adquirir o renovar información } \\
\text { sobre colocaciones y términos } \\
\text { específicos en letón (L1) }\end{array}$ & $\begin{array}{l}\text { - comprender } \\
\text { textos en } \\
\text { español (L2); } \\
\text { traducir del } \\
\text { español (L2) } \\
\text { al letón (L1) }\end{array}$ \\
\hline & $\begin{array}{l}\text { español-letón } \\
\text { para usuarios } \\
\text { de habla } \\
\text { hispana }\end{array}$ & codificación & $\begin{array}{l}\text { - adquirir información semántica } \\
\text { y gramatical sobre el letón (L2); } \\
\text { - adquirir o renovar información } \\
\text { sobre colocaciones y términos } \\
\text { específicos en español (L1) }\end{array}$ & $\begin{array}{l}\text { - } \text { redactar textos } \\
\text { en letón (L2); } \\
\text { - traducir del } \\
\text { español (L1) } \\
\text { al letón (L2) }\end{array}$ \\
\hline 3) & $\begin{array}{l}\text { letón-español } \\
\text { para usuarios } \\
\text { de habla } \\
\text { letona }\end{array}$ & codificación & $\begin{array}{l}\text { - adquirir información semántica } \\
\text { y gramatical sobre el español } \\
\text { (L2); } \\
\text { - adquirir o renovar información } \\
\text { sobre colocaciones y términos } \\
\text { específicos en letón (L1) }\end{array}$ & $\begin{array}{l}\text { - } \text { redactar textos } \\
\text { en español } \\
\text { (L2); } \\
\text { - traducir del } \\
\text { letón (L1) al } \\
\text { español (L2) }\end{array}$ \\
\hline 4) & $\begin{array}{l}\text { letón-español } \\
\text { para usuarios } \\
\text { de habla } \\
\text { hispana }\end{array}$ & decodificación & $\begin{array}{l}\text { - adquirir información semántica } \\
\text { y gramatical sobre el letón (L2); } \\
\text { - adquirir o renovar información } \\
\text { sobre colocaciones y términos } \\
\text { específicos en español (L1) }\end{array}$ & $\begin{array}{l}\text { - comprender } \\
\text { textos en letón } \\
\text { (L2); } \\
\text { - traducir del } \\
\text { letón (L2) al } \\
\text { español (L1) }\end{array}$ \\
\hline
\end{tabular}

Adamska-Sałaciak (2013: 224-225) propone incluir en el artículo lexicográfico, sea de codificación o de decodificación, los siguientes tipos de información para discriminar las equivalencias: 1) semántica (un sinónimo, un hiperónimo o una colocación), 2) sintáctica (categoría gramatical, transitividad, tipo de sujeto del verbo), y 3) pragmática (marcas diatópicas, diastráticas, diafásicas y diacrónicas). 
Las formas de proporcionar estos tipos de información incluida en la microestructura van a ser diferentes dependiendo de la función del diccionario. Por ejemplo, en todos los diccionarios bilingües se recomienda incluir la pronunciación, cuando no sea fácilmente deducible. Contrariamente a la creencia popular, se presentan estos casos tanto en español con préstamos de otras lenguas (hachís, Méjico, boutique) como en letón con fonemas no reflejados en la grafía y por tanto no deducibles (la $e$ 'cerrada' y la $e$ 'abierta'; tres diferentes fonemas escritos con la letra $o$; y, además, en ocasiones el tipo de entonación (entonación llana descendente vs. entonación rota) puede cambiar el significado de la palabra.

En un diccionario de decodificación, se ha de proporcionar la pronunciación del lema, mientras que, en un diccionario de codificación, la equivalencia en la lengua meta.

Algo similar ocurre con otros elementos de la información proporcionada en la microestructura del artículo lexicográfico. Se recomienda proporcionar la categoría y subcategoría gramatical (masculino, femenino, transitivo, intransitivo, pronominal) del lema (para decodificación) o de la equivalencia (para codificación). Si para la codificación se decide proporcionar estructuras sintácticas en las que puede o debe usarse la palabra, especialmente los verbos, se proporcionan, por supuesto, de las palabras en lengua meta, es decir, de las equivalencias.

En la Tabla 2 se resumen las principales diferencias de los elementos de la microestructura entre la codificación y la decodificación.

Tabla 2 Principales diferencias de los elementos de la microestructura

\begin{tabular}{|c|c|c|}
\hline \multicolumn{3}{|c|}{ Diferencias de elementos de la microestructura entre codificación y decodificación } \\
\hline Elemento de información lexicográfica & Codificación & Decodificación \\
\hline $\begin{array}{l}\text { Pronunciación, si no es fácilmente } \\
\text { deducible }\end{array}$ & de la equivalencia & del lema \\
\hline $\begin{array}{l}\text { Categoría y subcategoría gramatical } \\
\text { (masculino, femenino, transitivo, } \\
\text { intransitivo, pronominal) }\end{array}$ & de la equivalencia & del lema \\
\hline Frases de ejemplo de uso & de la equivalencia & del lema \\
\hline Paradigma de flexión & de la equivalencia & $\begin{array}{l}\text { no necesario; en caso de } \\
\text { proporcionar, del lema }\end{array}$ \\
\hline Irregularidad de la flexión & de la equivalencia & $\begin{array}{l}\text { no necesario; en caso de } \\
\text { proporcionar, del lema }\end{array}$ \\
\hline $\begin{array}{l}\text { Notas gramaticales o de particularidades } \\
\text { de uso }\end{array}$ & de la equivalencia & $\begin{array}{l}\text { no necesario; en caso de } \\
\text { proporcionar, del lema }\end{array}$ \\
\hline $\begin{array}{l}\text { estructuras sintácticas en las que puede o } \\
\text { debe usarse la palabra }\end{array}$ & de la equivalencia & no necesario \\
\hline Metalenguaje & $\begin{array}{l}\text { en la lengua } \\
\text { origen }\end{array}$ & en la lengua destino \\
\hline
\end{tabular}


Profundizando en la información gramatical, para la codificación letónespañol es recomendable proporcionar los siguientes elementos:

- la categoría y subcategoría gramatical de la equivalencia (para verbos incluye la transitividad y la pronominalidad);

- la predominancia de la forma del plural o singular de la equivalencia;

- enlace al paradigma de flexión del verbo completo;

- estructura sintáctica del verbo (preposición y valencia).

Para la codificación español-letón, a su vez, sería recomendable proporcionar:

- el tipo de declinación de sustantivos letones (del 1 al 6). Los sustantivos que en algún caso presentan cambios de palatalización de consonantes, se subrayan y se remite al paradigma de flexión completo;

- el tipo de conjugación de los verbos letones (I, II o III). Todos los verbos se subrayan y se remiten al paradigma de flexión completo;

- la predominancia de la forma del plural o singular de la equivalencia.

En cuanto a los criterios de selección y ordenación de palabras en la macro y microestructura, para las tareas de codificación es importante que se incluyan palabras frecuentes como lemas. Para las tareas de decodificación, en cambio, lo importante es que se cubra el léxico más extenso posible.

Una diferencia importante más entre la codificación y decodificación es el metalenguaje del diccionario, es decir, la lengua que se utiliza para proporcionar aclaraciones que sirven para discriminar las equivalencias y para proporcionar la información gramatical. Siempre debería ser la lengua nativa del usuario meta. En un diccionario electrónico se puede proporcionar en las dos lenguas.

Los ejemplos de uso que se proporcionan al usuario deben ser diferentes dependiendo del perfil del usuario. En un diccionario bilingüe, los ejemplos de uso no son obligatorios, pero son muy útiles para los que aprenden una lengua. Deben ilustrar la L2 del usuario, es decir, en un diccionario L2-L1 se deben incluir ejemplos del lema, y en un diccionario L1-L2 se deben incluir ejemplos de las equivalencias (Adamska-Sałaciak, 2013: 227). Dependiendo del tipo de usuario y de la complejidad de la palabra, los ejemplos se pueden tomar del corpus, más o menos adaptándolos, o bien inventarlos: el objetivo es cubrir la necesidad del usuario de la forma más eficaz posible. Nesi (1996: 204) insiste en que 'los ejemplos del diccionario pueden mejorar la productividad de la entrada lexicográfica solo si han sido cuidadosamente seleccionados para aclarar el significado y presentar las pautas gramaticales y colocacionales típicas.'

Según recomendaciones de Frankenberg-García (2015), es importante que los ejemplos de uso hayan sido escogidos para abordar los errores más comunes, además hay que diferenciar los tipos de ejemplos que ayuden al usuario en la codificación y en la decodificación, y hay que tener en cuenta que el usuario puede necesitar más que solo un ejemplo para entender el significado o el uso de la 
palabra. En los ejemplos de decodificación lo importante es ilustrar el significado típico y que las demás palabras que componen el ejemplo sean más frecuentes que la palabra ilustrada. A su vez, lo importante en los ejemplos de codificación es incluir las colocaciones y las estructuras gramaticales típicas.

En cuanto a las necesidades de los usuarios traductores, Fuentes (1997: 80-83) señala que un diccionario destinado a la decodificación no es lo mismo que un diccionario destinado a la traducción de L2 a L1, aunque aparentemente ambos tuvieran función pasiva, porque en este tipo de traducción es necesario activar un vocabulario pasivo en la lengua materna, por ejemplo, por razones estilísticas o de precisión, o se pueden necesitar palabras específicas que el usuario no conoce en su lengua materna, y también porque en el proceso de traducción se suelen producir interferencias de la lengua extranjera que hay que evitar. Si entre los grupos de usuarios meta incluimos a los traductores, la división de modelos de diccionarios en codificadores y decodificadores no es del todo estricta, porque en las tareas de traducción siempre existe una cierta necesidad de codificación, que debe ser solo semántica si se traduce a la L1, y semántica y sintáctica si se traduce a la L2.

\section{EJEMPLOS DE ARTÍCULOS LEXICOGRÁFICOS ESPAÑOL-LETÓN Y LETÓN-ESPAÑOL}

Poniendo en práctica las recomendaciones anteriores, a continuación, en la Figura 1 exponemos nuestra propuesta para un artículo lexicográfico en un diccionario electrónico español-letón decodificador, orientado a letonoparlantes con perfiles de estudiantes, profesores y traductores: el ejemplo del sustantivo regla. En esta ocasión, optamos por analizar ejemplos de lemas que son sustantivos porque los ejemplos de codificación de verbos son más complejos y merecerían una publicación aparte.

En la Figura 1, en la parte de arriba, debajo del lema (que aparece destacado en negrita), a la izquierda se sitúan las equivalencias ofrecidas, y, para las acepciones menos genéricas, en paréntesis y en color gris se ofrecen discriminadores de equivalencias, mezclando y combinando, de forma libre, los discriminadores semánticos, sintácticos y pragmáticos. A la derecha de cada equivalencia se ofrecen ejemplos de uso. Abajo, en un espacio separado, se ofrecen expresiones que contienen el lema, seguidos de sus equivalencias y los correspondientes ejemplos de uso; en algunos casos también se ofrecen discriminadores semánticos, sintácticos o pragmáticos y/o marcas pragmáticas. Las expresiones se pueden ordenar bien por orden alfabético o bien por orden semántico-lógico. Obsérvese que el metalenguaje es el letón y que los ejemplos de uso son en español e ilustran el uso típico del lema. 


\begin{tabular}{|c|c|c|}
\hline \multicolumn{3}{|l|}{ regla } \\
\hline f & noteikums, likums & $\begin{array}{l}\text { Los jugadores incumplían las reglas del juego. } \\
\text { Si quieres vivir aquí, respeta las reglas de } \\
\text { convivencia. Este cuadro surrealista rompe las } \\
\text { reglas de la física. }\end{array}$ \\
\hline (instruments) & lineāls & Una regla de estudiante mide $30 \mathrm{~cm}$ de largo. \\
\hline (sar.) & $\begin{array}{l}\text { mēnešreizes } \\
* \text { Tikai ar noteikto artikulu: } \\
\text { la regla. }\end{array}$ & $\begin{array}{l}\text { No existe una edad fija para que te venga la } \\
\text { regla, depende de cada chica. Ayer me bajó la } \\
\text { regla, y creo tener demasiada sangre. }\end{array}$ \\
\hline en regla & $\begin{array}{l}\text { kārtībā; derīgs; } \\
\text { sakārtots atbilstoši } \\
\text { likumam }\end{array}$ & $\begin{array}{l}\text { Él es inmigrante y todavía no tiene sus papeles } \\
\text { en regla. }\end{array}$ \\
\hline $\begin{array}{l}\text { pasaporte en } \\
\text { regla }\end{array}$ & derīga pase & $\begin{array}{l}\text { No puedo viajar porque no tengo mi pasaporte } \\
\text { en regla. }\end{array}$ \\
\hline en toda regla & $\begin{array}{l}\text { kārtīgi, pamatīgi; kā } \\
\text { pienākas }\end{array}$ & $\begin{array}{l}\text { Por consiguiente, necesitamos una investigación } \\
\text { en toda regla. }\end{array}$ \\
\hline $\begin{array}{l}\text { las cuatro } \\
\text { reglas }\end{array}$ & matemātiskās darbības & $\begin{array}{l}\text { Cuando lo sacaron del colegio, ya sabía las } \\
\text { cuatro reglas y leer de corrido. }\end{array}$ \\
\hline $\begin{array}{l}\text { por regla } \\
\text { general }\end{array}$ & parasti; kā likums & $\begin{array}{l}\text { Por regla general, las mujeres viven más que los } \\
\text { hombres. }\end{array}$ \\
\hline $\begin{array}{l}\text { regla de tres } \\
\text { (matem.) }\end{array}$ & $\begin{array}{l}\text { nezināmā aprēḳināšana; } \\
\text { proporcijas } \\
\text { pamatīpašíba }\end{array}$ & $\begin{array}{l}\text { Mediante la regla de tres puedes obtener un } \\
\text { número que desconoces. Para obtener un tanto } \\
\text { por ciento se construye una regla de tres simple. }\end{array}$ \\
\hline $\begin{array}{l}\text { regla de tres } \\
\text { (sar.) }\end{array}$ & $\begin{array}{l}\text { loǵiski spriežot; jādomā, } \\
\text { ka }\end{array}$ & $\begin{array}{l}\text { Este aparato es igual, y, por regla de tres, } \\
\text { tendría que valerte. }\end{array}$ \\
\hline
\end{tabular}

Figura 1 Propuesta de un artículo lexicográfico español-letón decodificador

Es un ejemplo decodificador, pero aun así contiene algunos rasgos de codificación, porque se ofrece cierta información gramatical básica que ayuda a utilizar el lema en frases (el género del sustantivo es $f$ ) y porque los ejemplos de uso han sido elegidos, primero, para ayudar a comprender mejor el significado del lema, pero también pueden ayudar a redactar frases típicas con el lema; se podría denominarlo codificación inversa (letón-español, cuando el diccionario en realidad es español-letón). Lo consideramos muy útil, sobre todo, para el aprendizaje de lengua en un nivel intermedio, cuando el estudiante primero busca qué significa una palabra y después aprende a utilizarla. También contribuye en las tareas de traducción.

En la Figura 2 podemos ver un ejemplo codificador español-letón del mismo lema regla, orientado a hispanohablantes que deseen expresarse en letón. 


\begin{tabular}{|c|c|c|}
\hline \multicolumn{3}{|l|}{ regla } \\
\hline (nom modirl & $\begin{array}{l}\text { likums } m .1 \\
\text { noteikums } m .1\end{array}$ & $\begin{array}{l}\text { Šim likumam ir izṇēmumi. Fizikas likumus nevar pārkāpt. } \\
\text { Spēēèāji pārkāpa spēles noteikumus. Ja tu gribi šeit } \\
\text { dzìvot, tev ir jāievēro kārtības noteikumi. } \\
\text { Skolēnu lineāli parasti ir } 30 \mathrm{~cm} \text { gari. }\end{array}$ \\
\hline $\begin{array}{r}\text { (menstruación) } \\
\text { (fam.) }\end{array}$ & $\begin{array}{l}\text { mēnešreizes } f .5 \\
\text { *USO: solo en pl. }\end{array}$ & $\begin{array}{l}\text { Katrai meitenei mēnešreizes var sākties citā vecumā. } \\
\text { Vakar man sākās mēnešreizes, un ir loti daudz asiṇu. }\end{array}$ \\
\hline en regla & $\begin{array}{l}\text { kārtībā; derīgs; } \\
\text { sakārtots } \\
\text { atbilstoši } \\
\text { likumam }\end{array}$ & $\begin{array}{l}\text { Viṇš ir imigrants, un vina papīri nav kārtībā. Viṇš nav } \\
\text { sakārtojis savus dokumentus. }\end{array}$ \\
\hline $\begin{array}{l}\text { pasaporte en } \\
\text { regla }\end{array}$ & derīga pase & Es nevaru celot, jo man nav derīgas pases. \\
\hline en toda regla & $\begin{array}{l}\text { kārtīgi, pamatīgi; } \\
\text { kā pienākas }\end{array}$ & $\begin{array}{l}\text { Šoreiz būs jāveic pamatīgs pētījums, nevis tikai } \\
\text { atrakstīšanās keksīša pēc. } \\
\text { Būs bēres, kā pienākas: uzklāsim bagātigu galdu un } \\
\text { mācītājs teiks runu. }\end{array}$ \\
\hline $\begin{array}{l}\text { las cuatro } \\
\text { reglas }\end{array}$ & $\begin{array}{l}\text { matemātiskās } \\
\text { darbības }\end{array}$ & $\begin{array}{l}\text { Sākumskolā bērni mācās matemātiskās darbības - } \\
\text { saskaitīt, atṇemt, reizināt un dalīt. }\end{array}$ \\
\hline $\begin{array}{l}\text { por regla } \\
\text { general }\end{array}$ & $\begin{array}{l}\text { parasti; } \\
\text { kā likums }\end{array}$ & $\begin{array}{l}\text { Parasti sievietes dzīvo ilgāk nekā vīrieši. } \\
\text { Spējīgākie augstkolu absolventi, kā likums, uzreiz aiziet } \\
\text { uz ražojošām firmām. }\end{array}$ \\
\hline $\begin{array}{l}\text { regla de tres } \\
\text { (matem.) }\end{array}$ & $\begin{array}{l}\text { nezināmā } \\
\text { aprēḳināšana; } \\
\text { proporcijas } \\
\text { pamatīpašība }\end{array}$ & $\begin{array}{l}\text { Vispirms vajag sastādīt proporciju un tad aprēkināt } \\
\text { nezināmo. } \\
\text { Proporcijas pamatīpašību izmanto nezināmā locekḷa } \\
\text { aprēeināšanā. }\end{array}$ \\
\hline $\begin{array}{l}\text { regla de tres } \\
\text { (lógica) }\end{array}$ & $\begin{array}{l}\text { loǵiski spriežot; } \\
\text { jādomā, ka }\end{array}$ & $\begin{array}{l}\text { Loǵiski spriežot, jaunai frizūrai vajadzētu novērst } \\
\text { uzmanību no izmainām figūrā. } \\
\text { Šis aparāts ir tieši tāds pats, jādomā, ka derēs. }\end{array}$ \\
\hline
\end{tabular}

Figura 2 Propuesta de un artículo lexicográfico español-letón codificador

Primero, obsérvese que el metalenguaje ahora es el español y los ejemplos de uso se ofrecen en letón, ilustrando el uso típico de las palabras propuestas como equivalencias. Ha desaparecido la indicación del género del lema $(f)$, porque para un hispanohablante no es necesario y puede molestar. En cambio, ahora aparece información gramatical sobre las equivalencias ( $m .1$ y $f .5)$. La letra $m$ significa un sustantivo masculino, y la letra $f$, un sustantivo femenino, de modo que estamos informando al usuario del diccionario sobre el género de cada equivalencia. La cifra que sigue indica el tipo de declinación del sustantivo. En lengua letona los sustantivos se agrupan en 6 tipos de declinaciones, es decir, existen 6 modelos diferentes para declinar un sustantivo. Para poder declinar la palabra y poder usarla en una frase, es necesario saber a qué tipo de declinaciones pertenece. 
En esta propuesta ofrecemos esta información gramatical para cada una de las equivalencias en el cuadro de arriba, pero, en un caso ideal, se ofrecería también para las palabras incluidas en las equivalencias de las expresiones en el cuadro de abajo.

Para un ejemplo de diccionario en la dirección contraria, letón-español, veamos el sustantivo letón likums, que en el ejemplo anterior fue la primera equivalencia ofrecida para traducir el lema regla. En la Figura 3 tenemos el ejemplo de decodificación, y en la Figura 4, de codificación.

En la Figura 3 proporcionamos información gramatical básica sobre el lema: es un sustantivo masculino de primer tipo de declinación (m.1). No proporcionamos información gramatical sobre las equivalencias porque para un hispanohablante no es necesario y no es lo que está buscando. Los ejemplos de uso están en letón, ilustrando el uso típico del lema en textos escritos en letón. El metalenguaje es el español, pero en este ejemplo concreto se proporcionan abreviaciones internacionales de marcas pragmáticas que son comprensibles en ambas lenguas.

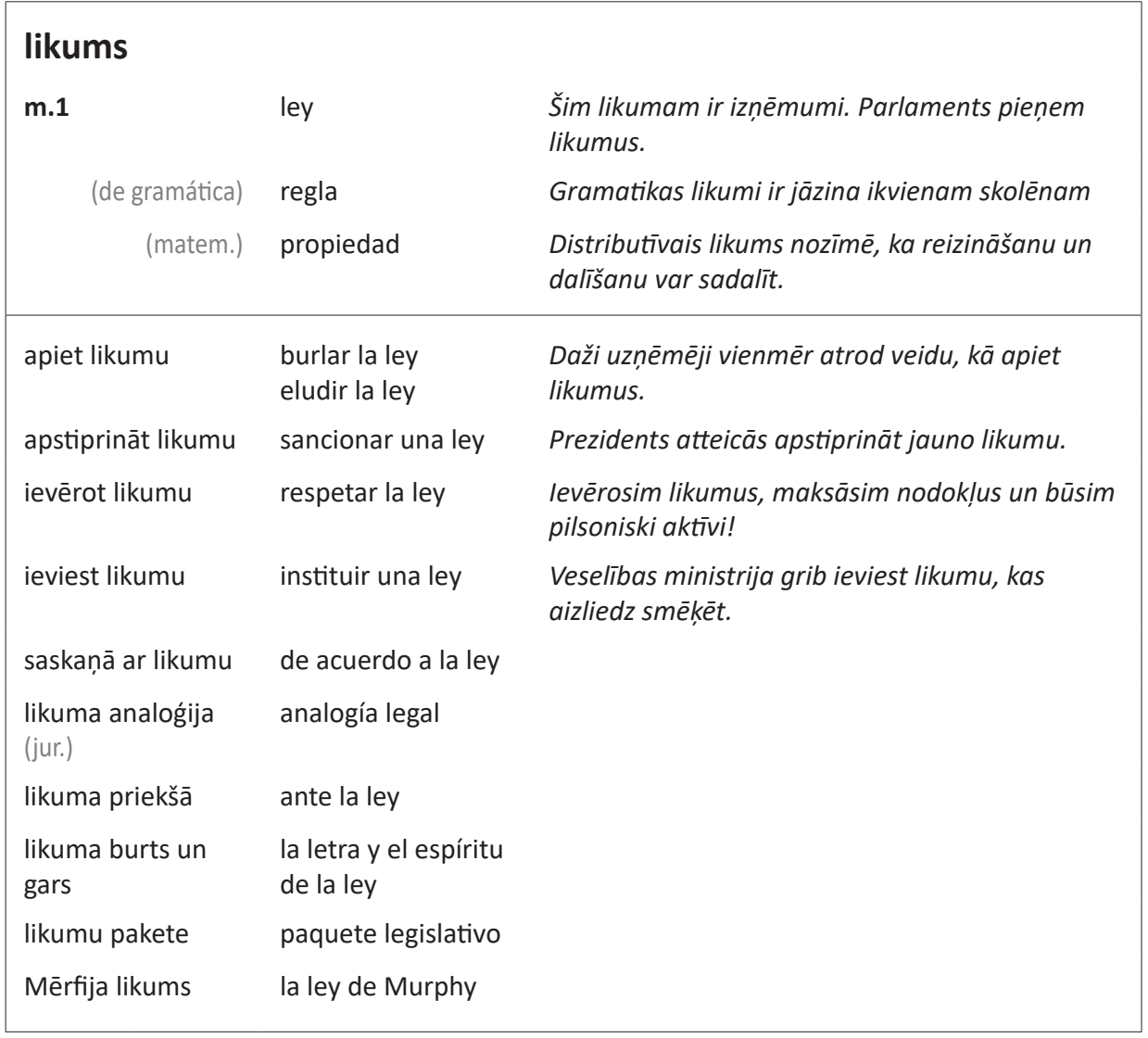

Figura 3 Propuesta de un artículo lexicográfico letón-español decodificador 
Por último, en la Figura 4 veamos el ejemplo del mismo lema likums. Hemos acortado un poco la parte de las expresiones, porque en este caso, las expresiones y sus equivalencias son idénticas a las que se han expuesto en la Figura 3, salvo los ejemplos de uso que no se proporcionan en letón sino en español. Obsérvese que ya no ofrecemos información gramatical sobre el lema, pero sí la ofrecemos para cada una de las equivalencias.

\begin{tabular}{|c|c|c|}
\hline \multicolumn{3}{|l|}{ likums } \\
\hline \multirow{3}{*}{$\begin{array}{r}\text { (de gramática) } \\
\text { (matem.) }\end{array}$} & ley $f$ & El Parlamento aprueba leyes. \\
\hline & regla $f$ & ¿Por qué son importantes las reglas gramaticales? \\
\hline & propiedad $f$ & $\begin{array}{l}\text { El concepto de propiedad distributiva se emplea en el } \\
\text { campo del álgebra. }\end{array}$ \\
\hline \multirow[t]{2}{*}{ apiet likumu } & burlar la ley & $\begin{array}{l}\text { Quien no sabe burlar la ley es que carece de } \\
\text { imaginación. }\end{array}$ \\
\hline & eludir la ley & $\begin{array}{l}\text { Algunos empresarios encontraron la forma de eludir } \\
\text { esta ley. }\end{array}$ \\
\hline apstiprināt likumu & $\begin{array}{l}\text { sancionar } \\
\text { una ley }\end{array}$ & $\begin{array}{l}\text { El Rey sanciona las leyes aprobadas por las Cortes } \\
\text { Generales. }\end{array}$ \\
\hline
\end{tabular}

Figura 4 Propuesta de un artículo lexicográfico letón-español codificador (acortado)

\section{CONCLUSIONES}

Las principales diferencias en la microestructura entre la codificación y decodificación es la cantidad y variedad de los elementos lexicográficos ofrecidos al usuario meta, el metalenguaje que siempre debe ser la lengua que mejor domina el usuario, así como la lengua que se utiliza para proporcionar los ejemplos de uso. Por tanto, si nuestro objetivo es crear un modelo bidireccional codificador y decodificador y al mismo tiempo no saturar o molestar a algún grupo de usuarios, la única posibilidad es considerar un diccionario electrónico, con posibilidades técnicas para ocultar o mostrar una parte de la información dependiendo del perfil del usuario, facilitando la lectura.

En la macroestructura, los criterios de selección de lemas difieren radicalmente, por tanto, si nuestro objetivo es crear un modelo bidireccional codificador y decodificador, es necesario encontrar un equilibrio entre el criterio de frecuencia y el deseo de cubrir el léxico más extenso posible.

Comparando los elementos lexicográficos y las posibles estructuras lexicográficas de artículos en las lenguas español y letón, cabe concluir que se observan las diferencias en los elementos de información gramatical a incluir para facilitar la codificación en una lengua y en otra, por ejemplo, para palabras letonas se ofrecería información para declinar los sustantivos; al mismo tiempo, es posible estructurar la información en una forma parecida tanto para usuarios 
de una lengua como para la otra, lo cual facilitaría la creación de un diccionario electrónico destinado para ambos perfiles de usuarios simultáneamente.

La publicación del presente artículo ha contado con el apoyo del proyecto ' $\mathrm{La}$ lengua letona' (Nr. VPP-IZM-2018/2-0002) dentro del Programa Nacional de Investigaciones.

\section{REFERENCIAS BIBLIOGRÁFICAS}

Adamska-Sałaciak, A. (2013) Issues in Compiling Bilingual Dictionaries. En H. Jackson (ed.) The Bloomsbury Companion to Lexicography. London: Bloomsbury.

Atkins, B. T. S. y Rundell, M. (2008) The Oxford Guide to Practical Lexicography. Oxford: Oxford University Press.

Balode, I. (2012) Vācu-latviešu un latviešu-vācu leksikogrāfija (1991-2010). En J. Baldunčiks (ed.) Vārdnīcu izstrāde Latvijā: 1991-2010. Pētījums. Rīga: Latviešu valodas ağentūra.

Bogaards, P. (2003) Uses and users of dictionaries. En P. A. Sterkenburg, (ed.) Practical Guide to Lexicography. Amsterdam, Philadelphia: John Benjamins Publishing.

Brjuhovecka, G. y Rozenberga, M. (2015) Spāṇu valodas leksikogrāfijas vēsture un tās attīstības perspektīvas Latvijā. En J. Baldunčiks, A. Veisbergs (eds.) Valsts valodas komisijas raksti. 7. Sējums. Vārdnīcas un valoda. Rìga: Zinātne.

Cano Ginés, A. (2003) Contribuciones lexicográficas al español como lengua extranjera. Tesis Doctoral. Madrid: Universidad Complutense de Madrid. Disponible en http:/ / eprints.ucm. es/4833/ [Consultado el 20 de septiembre de 2016].

Frankenberg-García, A. (2015) Corpus examples for language comprehension and production. International Journal of Lexicography, 28 (4): 490-512. Oxford: Oxford University Press. Disponible en http://dx.doi.org/10.1093/ijl/ecv013 [Consultado el 20 de septiembre de 2016].

Fuentes Morán, M. T. (1997) Gramática en la lexicografía bilingüe: Morfología y sintaxis en diccionarios español-alemán desde el punto de vista del germanohablante. Tübingen: Max Niemeyer Verlag.

Haensch, G. (1997) Los diccionarios del español en el umbral del siglo XXI. Salamanca: Ediciones Universidad de Salamanca.

Lew, R. (2004) Which dictionary for whom? Receptive use of bilingual, monolingual and semibilingual dictionaries by Polish learners of English. Poznan: Motivex. Disponible en https:// www.researchgate.net/publication/49250252 [Consultado el 15 de marzo de 2019].

Medina Guerra, M. a A. (coord.) (2003) Lexicografía española. Barcelona: Ariel.

Nesi, H. (2013) Researching Users and Uses of Dictionaries. En H. Jackson (ed.) The Bloomsbury Companion to Lexicography. London: Bloomsbury.

Nesi, H. (1996) The Role of Illustrative Examples in Productive Dictionary Use. Dictionaries: Journal of the Dictionary Society of North America, 17: 198-206. Disponible en https:// www.researchgate.net/publication/236710547_The_Role_of_Illustrative_Examples_in Productive_Dictionary_Use [Consultado el 15 de junio de $20 \overline{19}$ ].

Nielsen, S. (2013) The future of the dictionaries, the dictionaries of the future. En H. Jackson (ed.) The Bloomsbury Companion to Lexicography. London: Bloomsbury.

Porto Dapena, J. A. (2002) Manual de técnica lexicográfica. Madrid: Arco/Libros. 


\title{
RECURSOS DIGITALES
}

[En línea 1] Līdzsvarots mūsdienu latviešu valodas tekstu korpuss. Latvijas Universitātes Matemātikas un informātikas institūta Mākslīgā intelekta laboratorija. Disponible en www.korpuss.lv. [Consultado el 15 de marzo de 2019].

[En línea 2] Corpus de Referencia del Español Actual de la Real Academia Española. Disponible en http://corpus.rae.es/creanet.html [Consultado el 15 de marzo de 2019].

\section{ENCODING AND DECODING IN BILINGUAL LEXICOGRAPHY: COMPILING A NEW SPANISH-LATVIAN DICTIONARY}

\begin{abstract}
Based on the proposal of the lexicographer Sandro Nielsen (2013) that a dictionary should be redefined as a complex reference tool that fulfils certain lexicographic functions, as well as on the conclusion of the Spanish author Porto Dapena (2002) that each dictionary, depending on its purpose, should offer different content and structure, this paper is dedicated to bilingual lexicography emphasizing the differences that exist between the communicative lexicographic function of decoding (comprehension or interpretation) and the function of encoding (expression). The scientific literature regarding lexicographical theory and praxis is studied in order to identify the macrostructural and microstructural elements which are needed for encoding and decoding purposes in Spanish and in Latvian, highlighting the practical necessity to search for new solutions for encoding tasks, especially referring to bilingual dictionaries, as well as deepening the understanding of language contact between Spanish and Latvian speaking population. This paper is part of the national research project 'Latvian language' with the aim to compile a new Spanish-Latvian/LatvianSpanish bilingual dictionary considering creation of materials for different user profiles.
\end{abstract}

Key words: bilingual lexicography, decoding, encoding, electronic dictionary

Gunta Brjuhovecka (Mag. Philol., investigadora) trabaja actualmente en la Universidad de Letonia. Sus intereses académicos incluyen la lexicografía y la lingüística contrastiva. Correo electrónico: jekabsone.gunta@gmail.com 